Original Research Article

\title{
A study on management of type 2 diabetic patients with complications
}

\author{
Shruti Vihang Brahmbhatt*, Bhagya M. Sattigeri
}

Department of Pharmacology, SBKS MI and RC, Sumandeep Vidyapeeth-Piapria, Vadodara, Gujarat, India

Received: 31 May 2019

Revised: 29 June 2019

Accepted: 02 July 2019

\section{*Correspondence to:}

Dr. Shruti Vihang Brahmbhatt, Email: dr.shruti1988@ gmail.com

Copyright: (C) the author(s), publisher and licensee Medip Academy. This is an openaccess article distributed under the terms of the Creative Commons Attribution NonCommercial License, which permits unrestricted noncommercial use, distribution, and reproduction in any medium, provided the original work is properly cited.

\begin{abstract}
Background: Diabetes is a major public health problem both in developing and non-developing countries across the world. It is a chronic disease, which in long term causes several complications resulting in poly pharmacy for its management. Hence, this study was determined to analyze the drug utilization pattern for the management of type 2 diabetes with complications.

Methods: A prospective, observational and non-interventional study was carried out in 100 diabetic patients with one or other complications admitted in medicine wards at Dhiraj Hospital. Patients who signed informed consent form were only included in the study. All the data were recorded from patients' case files and analyzed.

Results: Result of total 100 patients, maximum number $52(52 \%)$ were falling in group of $61-70 \mathrm{~kg}$ and only $2(2 \%)$ in $81-90 \mathrm{~kg}$. Out of 100 diabetic patients, 40 $(40 \%)$ were managed with insulin in addition to oral antidiabetic agents, $37(37 \%)$ were managed with only Oral Hypoglycemic Agents (OHA) and 23 (23\%) were managed with only insulin. The most commonly prescribed oral antidiabetic group of drug was Biguanides in $60(60 \%)$ and most prescribed insulin was short acting Insulin in $40(40 \%)$ patients.

Conclusions: The diabetic patients are more prone to cardiovascular and other complications leading to a co morbid condition. The poly pharmacy is likely to occur in diabetic patients suffering with secondary complications. Therefore, intense blood sugar control with proper education can prevent the co morbid state and finally helps in reducing the economic burden.
\end{abstract}

Keywords: Drug utilization, Insulin, Oral hypoglycaemic agents, Type 2 Diabetes

\section{INTRODUCTION}

Diabetes, a major non-communicable disease has been a problem of both developing and non-developing countries. ${ }^{1-3}$ Long standing uncontrolled diabetes is known to cause microvascular and macrovascular complications affecting the major organs like eyes, kidney and brain along with the cardiovascular complications like hypertension and dyslipidemia. ${ }^{4}$

Lack of awareness on the importance of glycaemic control, importance of adherence to medications, financial constraints or self-negligence could be the common causes that may lead to complications in these individuals. Similarly, the uncontrolled glycaemic state on a long run results into the development of co morbid conditions which further worsen the health state and adds to the expense in health management. ${ }^{4-8}$

Several research and review studies have been performed to evaluate the prevalence and the drug utilized in the management of type 2 diabetes. Further, studies have been conducted to provide useful insights into the present prescribing trends, rational and irrational medications. .,9-11 $^{-1}$ such studies can help us to compare the treating strategies available in this common condition and to prepare standard 
treatment guidelines to treat and prevent the related complication of diabetes. Irrational use of medicines remains a major concern in practice applicable to diabetes as well, where patients are invariably suffering with comorbid conditions requiring more than one medication thus landing in to practice of polypharmacy.

Similarly, with the compromised immunity, the diabetic individuals who are more prone for infections succumb to the antibiotic resistance and adverse effects in cases where irrational or inappropriate antimicrobials are used, thus resulting into economic burden in their health management. ${ }^{5}$ Such situations further contribute to non-adherence of medications and worsen the diabetic control. Hence, the study has been taken up to evaluate the drug pattern or the prescription pattern in patients of type 2 diabetes with associated complications.

\section{METHODS}

The study was initiated after obtaining the approval from the Institutional Ethic Committee (SVIEC). Considering the inclusion and exclusion criteria, the type 2 diabetic patients with complications aged 18 and above and willing to give inform consent were included while the type 2 diabetic patients without complications, patients with type-1 diabetes and pregnancy induced diabetes were excluded from the study.

The prospective non-interventional study was conducted in a total of 100 diabetic patients with presence of complications at Dhiraj Hospital, a tertiary care teaching rural hospital affiliated to SBKS MI and RC, run under Suman deep Vidyapeeth, an institution deemed to be University over a period of 15 months from November 2012 to May 2014 After explaining the purpose and nature of the study to the enrolled patients, their demographic details like age, gender, occupation, medical, personal, family and past history along with the treatment details obtained from the patients' case files were recorded in the case record form and subjected for percentage wise data analysis.

\section{Study type}

This was a prospective, observational and noninterventional study.

\section{Study site}

The study was conducted at Dhiraj Hospital, a tertiary care teaching rural hospital affiliated to SBKS MI and RC, run under Sumandeep Vidyapeeth, an Institution Deemed to be University.

\section{Study population and Inclusion and Exclusion Criteria}

The study was carried out in 100 diabetic patients with presence of other complications and admitted in medicine wards of Dhiraj Hospital, Sumandeep Vidyapeeth.

\section{Inclusion criteria}

- The patients diagnosed with type 2 diabetes with presence of other complications

- The patients aged above 18 years

- The patients who are willing to sign the Written Informed Consent Form

\section{Exclusion Criteria}

- The patients having only type 2 diabetes with no complication.

- Patients below 18 years of age

- Patients who are not ready to sign to written Informed Consent Form.

- Patients having type 1 diabetes

- Pregnancy Induced Diabetes.

\section{RESULTS}

The study included total 100 diabetic participants; out of them $10(10 \%)$ participants were falling in group of 50-60 kg of weight, followed by $52(52 \%)$ in $61-70 \mathrm{~kg}, 36(36 \%)$ in $71-$ $80 \mathrm{~kg}$ and only $2(2 \%)$ in $81-90 \mathrm{~kg}$ of weight. All the patients had past history of diabetes. Out of them, $58(58 \%)$ had past history of diabetes less than five years and $37(37 \%)$ patients had diabetes for more than 5 and less than 10 years, while only $5(5 \%)$ patients had suffered with diabetes for more than 10 years.

Authors observed that of the 100 patients, 89 (89\%) patients were regularly taking the medication for the diabetes management, while $10(10 \%)$ patients were irregular and 1 (1\%) patient was not aware about it. Out of 89 patients who were regular with their medications, 35 patients were on Metformin, 14 patients were on Metformin in combination with Glimepiride, Pioglitazone or Sitagliptin while 40 patients were only on insulin preparations. It was observed that, only $62(62 \%)$ patients were having control on intake of diet, while $38(38 \%)$ were not having diet control or unaware of diet control and its importance in Diabetes Mellitus.

The diabetic patients were admitted for the various medical conditions in the medicine wards like Hypertension, Chronic Kidney Disease, Urinary Tract Infections, Parkinsonism, Pleural effusion etc (Table 1). In the study out of all the 100 patients admitted in medicine wards $40 \%$ were managed with insulin in addition of oral antidiabetic agents, $37 \%$ were managed with only oral hypoglycemic agents (OHA) and $23 \%$ were managed with only insulin.(Figure 1) Most cases included in the study were treated with Biguanides $(60 \%)$ and Sulfonylurea (22\%) followed by Thiazolidinediones (4\%), Meglitinide (2\%), $\alpha$-glucosidase inhibitors (10\%), Dipeptidyl Peptidase-4 (DPP4) inhibitor (2\%), Sodium-Glucose Linked Transporter-2 (SGLT-2) inhibitor (2\%).

Among the 100 patients who received insulin, it was observed that most commonly prescribed insulin was short acting insulin (e.g. regular) (40\%) followed by rapid acting 
insulin (eg. aspart, lispro) (13\%), intermediate acting insulin (eg. isophane) (5\%), and long acting insulin (eg. glargine, lantus) (5\%). Overall the study focused on drug utilization in diabetic patients having complications.

Table 1: Diagnosis of the patients admitted in medicine wards.

\begin{tabular}{|l|l|}
\hline Diagnosis of diabetic patient admitted in medicine ward & Number \\
\hline Uncontrolled diabetes with hypertension & 15 \\
\hline ARF, CKD, hypertension, Diabetic nephropathy, cirrhosis of liver & 12 \\
\hline UTI, hypertension & 12 \\
\hline Viral fever, PUO, hypertension & 12 \\
\hline LRTI, pleural effusion, pulmonary edema, COPD, hypertension, Hypothyroidism and Polymyositis & 10 \\
\hline Acute Gastroenteritis and hypertension & 07 \\
\hline Cataract and hypertension & 07 \\
\hline BPH, carcinoma of Prostate, hypertension & 04 \\
\hline Angina, IHD, MI, hypertension & 03 \\
\hline Cerebrovascular stroke, hypertension & 03 \\
\hline Diabetic foot, hypertension & 03 \\
\hline Dyslipidemia and hypertension & 03 \\
\hline Parkinsonism & 02 \\
\hline Generalised tonic clonic convulsion(GTC) & 03 \\
\hline Septicaemia & 01 \\
\hline Osteoarthritis & 01 \\
\hline Aplastic anemia & 01 \\
\hline Abcess & 01 \\
\hline
\end{tabular}

Out of 100 patients, antihypertensives were administered with $91(91 \%)$, while antibiotics with $68(68 \%)$ patients, anti-ulcer agents in $56(56 \%)$, hypolipidemic drugs in $45(45 \%)$, multivitamins in $43(43 \%)$ patients, antiplatelet agents in 20 (20\%), analgesics in $18(18 \%)$, antiemetic drugs in $18(18 \%)$, glucocorticoids in $14(14 \%)$, antiasthmatic in $12(12 \%)$, antihistaminic drugs in $10(10 \%)$, antispasmodics in $8(8 \%)$, antianginal drugs in $4(4 \%)$, muscle relaxants in $2(2 \%)$, antiarrhythmic drug in $1(1 \%)$ and intravenous fluids in 40 $(40 \%)$ patients. (Figure 2 ).

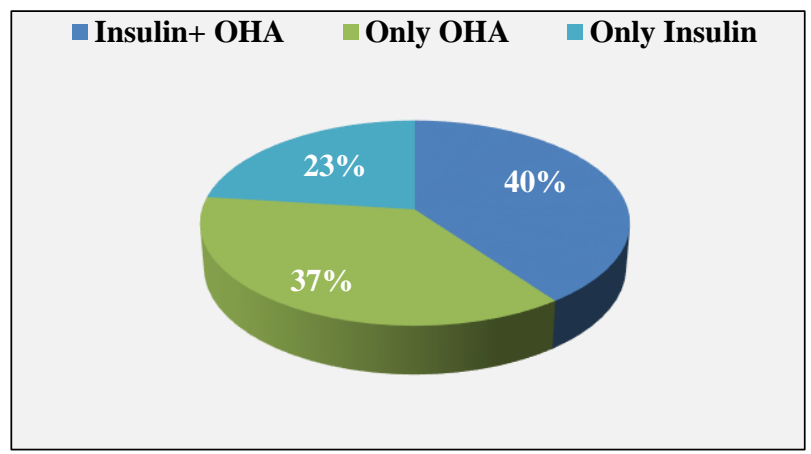

Figure 1: percentage of prescribed OHA and Insulin.

Considering gender, the mean $\mathrm{S}$. Cr was $0.81 \mathrm{mg} / \mathrm{dl}$ and $0.93 \mathrm{mg} / \mathrm{dl}$ in female and male respectively in AM group. In GM group the mean $\mathrm{S} . \mathrm{Cr}$ values were $0.82 \mathrm{mg} / \mathrm{dl}$ and $0.93 \mathrm{mg} / \mathrm{dl}$ in female and male respectively. There was no significant difference in initial S.Cr levels (Table 2 and Figure 2).

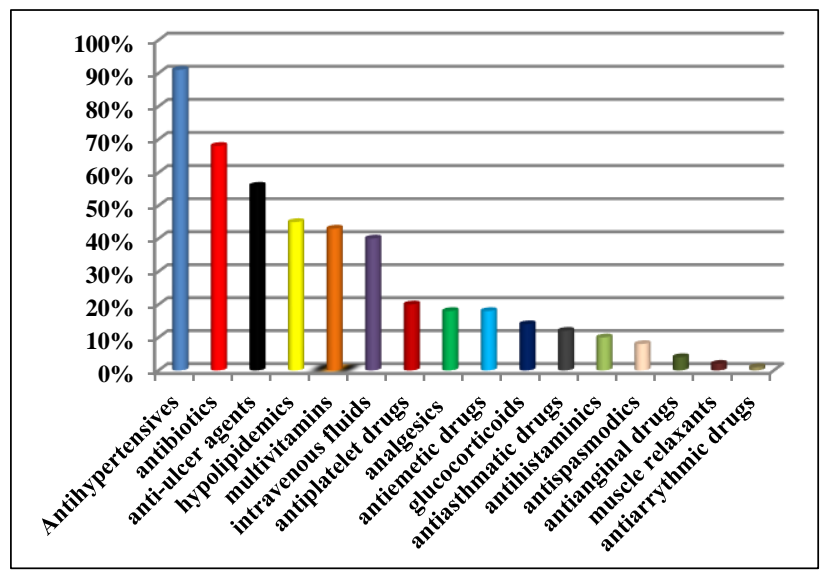

Figure 2: percentage of different prescribed drugs.

\section{DISCUSSION}

The present study focussed on the management of diabetes and the associated complications where, it was found that maximum patients were aged above 60 years, which was similar to the observations found by Brahmbhatt $\mathrm{S}$ et al. ${ }^{5}$ In contrast to this, a study conducted by Singh et al, and Das. $\mathrm{S}$ et al, showed that higher numbers of diabetic patients were falling in the age group of 50-59 years. ${ }^{3,12}$

Increased association of Obesity in Diabetes has been observed in last few decades which has been considered as one of the major risk factors for the occurrence of diabetes. ${ }^{13}$ In this study, it was found that majority of the 
patients weighed around 61-70 kgs with very few $2(2 \%)$ patients with overweight $(2 \%)$.

We have observed that of the enrolled 100 patients, in only $5 \%$ diabetes existed for more than 10 years while the remaining individuals suffered for less than 5 years which was in contrast to the observations made by Adhikari et al, who showed that highest number of the patients lived with diabetes for more than 10 years and less number of patients with a period of less than 5 years. ${ }^{14}$

It is essential that every diabetic patient is counselled with the importance of lifestyle modifications including diet and exercise along with medication he/she receives. And it has been proved through several studies that sedentary lifestyle and erratic food habits contribute to a great extent in development of obesity and the co morbid conditions including diabetes. We have observed through this study that more than half of the patients, $62(62 \%)$ were aware of the diet and exercise control in diabetes. Further, it was also observed that $2 / 3^{\text {rd }}$ of the patients $89(89 \%)$ were observed to be particular about their adherence to intake of medications. $^{5}$

On analysing the prescriptions, we observed that majority of diabetic individuals were managed with both oral and parenteral preparations. The preferred oral preparation was Biguanides (Metformin) followed by Sulfonylureas. These observations of this study were similar to that of observations made by Karthikeyan et al. ${ }^{15}$ It was also observed that in these hospitalised individuals, regular insulin was preferred the maximum to obtain the glycaemic control, these observations of this study were very much similar to those of $\mathrm{S}$. Das et al. ${ }^{3}$ which is also observed in other studies. ${ }^{16-18}$

Further, it was observed that the enrolled diabetic patients were complicated with either hypertension, chronic kidney disease, urinary tract infections, parkinsonism and pleural effusion which were almost similar to the observations made by Karthikeyan et al, and Adhikari et al. Further, it was also observed that most of the patients received multiple drugs adding to the practice of polypharmacy. The highest number of prescribed medicines included antihypertensive drugs, antibiotics, anti-ulcer agents and hypolipidemic agents while, in contrast, the observations made by Adhikari et al, showed that antibiotics and drugs related to gastrointestinal system were less prescribed. ${ }^{14-15}$

\section{CONCLUSION}

The chronic metabolic disorder with immune compromised state, all diabetic individuals are prone to the complications with uncontrolled glycaemic status resulting in co morbid conditions which forces and the practice of polypharmacy that succumbs the individuals to suffer with problems like adverse drug reaction, drug interactions and drug resistance. Therefore, it has been essential to have proper treatment guidelines along with regular counselling to the diabetic patients pertaining to the importance of adherence to medications and patient compliance that can refrain them from long standing complications and lessening with their economic burden.

Funding: No funding sources

Conflict of interest: None declared

Ethical approval: The study was approved by the Institutional Ethics Committee

\section{REFERENCES}

1. Ramesh R, Kumar SV, Gopinath S, Gavaskar B, Gandhiji G. Diabetic knowledge of rural community and drug utilization pattern in a tertiary care hospital. Int. J. of Pharm. and Life Sci. 2011; 2(1):531-535.

2. Vijayakumar S., Sasikala M., Mohammed Saleem T.S. and Gauthaman K. Prevalence of diabetes in Sikkim and Darjeeling district of west Bengal and role of risk factor associated with it-A preliminary survey. IJCP. 2008;1(3):36-40.

3. Das S, Haroled Peter PL, Bhavani ML, Naresh P, Ramana MV. Age- and Sex-related Prevalence and Drug Utilization Pattern in the Management of Type 2 Diabetes Mellitus and its Comorbidity with Cardiovascular Diseases: A Comparative Study. Indian J Pharm Sci. 2015;77(4):478-484.

4. Hussain Z, Sana A, Mohammed S, Razzaq MA. Patterns of drug therapy among diabetic hypertensive patients with other complications. Int $\mathrm{J}$ Pharm Sci. 2014;6(6):270-7.

5. Brahmbhatt SV, Sattigeri BM, Nil AK, Parikh DP, Shah HS. A prospective study on drug utilization pattern \& rationality in treatment of type II diabetes mellitus: a population based analysis. Int J Res Med Sci. 2014 Jul;2(3):983-7.

6. Ajayi EA, Ajayi AO. Pattern and outcome of diabetic admissions at a federal medical center: a 5-year review. Ann Afric Med. 2009;8(4):271-5.

7. Fitzgerald JT, Anderson RM, Davis WK. Gender differences in diabetes attitudes and adherence. Diabetes Educat. 1995;21(6):523-9.

8. Sharma R, Grover VL, Chaturvedi S. Recipe for diabetes disaster: a study of dietary behaviors among adolescent students in south Delhi, India. Int $\mathbf{J}$ Diabetes Develop Countr. 2011 Feb 1;31(1):4-8.

9. Adhikari AK, Vidyasagar G, Rathore DS, Balaram G. Drug utilization review of anti-diabetic drugs in in patients and outpatients of a tertiary care hospital of India. Ind J Hosp Pharm. 2011;48:32-4.

10. Naikwade NS, Balsara II. Study of prevalence and pattern of drug utilization of antidiabetic drugs used in type 2 diabetes mellitus in an endocrine research centre. Ind J Hosp Pharm. 2006;XLIII:69-70.

11. Thiyagu R, Arumani R, Narmadha T, Ramalakshmi S, Sundaran TS. Drug use pattern study of anti-diabetics in outpatient setting of a secondary care hospital. Indian J Hosp Pharm. 2008;45:176-9.

12. Singh PS, Sharma H, Zafar KS, Singh PK, Yadav SK, Gautam RK, et al. Prevalence of type 2 diabetes mellitus in rural population of India- a study from 
Western Uttar Pradesh. Int J Res Med Sci. 2017;5(4):1363-7.

13. Babu GR, Murthy GV, Ana Y, Patel P, Deepa R, Neelon SE, Kinra S, Reddy KS. Association of obesity with hypertension and type 2 diabetes mellitus in India: A meta-analysis of observational studies. World J Diabetes. 2018 Jan 15;9(1):40-52.

14. Adhikari S, Shrestha S, Shakya R, Koirala N. Prevalance of Chronic Complications and Drug Utilization Pattern of Type II Diabetes Mellitus. M J Diab. 2017;2(1):006.

15. Karthikeyan V, Maadhusudhan S, Selvamuthu kumran S. Saudi J Med Pharm Sci. 2016;2(5):100-7.

16. International Diabetes Federation. Glucose control: Oral therapy. In, Clinical Guidelines Task Force.
Global Guidelines for Type 2 Diabetes. Ch. 9. Brussels: International Diabetes Federation; 2005.

17. Royal College of Physicians. Type 2 Diabetes. National Clinical Guideline for Management in Primary and Secondary Care (Update). London: The Lavenham Press Ltd.; 2008.

18. American Diabetes Association. Standards of medical care in diabetes-2009. Diabetes care. 2009 Jan;32(Suppl 1):S13-61.

Cite this article as: Brahmbhatt SV, Sattigeri BM. A study on management of type 2 diabetic patients with complications. Int $\mathrm{J}$ Basic Clin Pharmacol 2019;8:1870-4. 